\title{
Dopamine agonists and ischemic complications in Parkinson's disease: a nested case-control study
}

\author{
Maurits E. L. Arbouw • Kris L. L. Movig • \\ Henk-Jan Guchelaar • Cees Neef • Toine C. G. Egberts
}

Received: 17 February 2011 /Accepted: 7 June 2011 / Published online: 22 July 2011

(C) The Author(s) 2011. This article is published with open access at Springerlink.com

\begin{abstract}
Background It has been suggested that ergoline dopamine agonists can cause ischemic complications. The effect of dopamine agonists in general on the prevalence of ischemic events in patients with Parkinson's disease (PD) has not been studied.

Objective Our aim was to investigate the association between the use of dopamine agonists and hospitalization due to ischemic events in patients with PD.

Methods We performed a nested case-control study using the PHARMO Institute for Drug Outcome Research database. All patients issued at least one prescription for levodopa after the age of 55 years between 1994 and 2006
\end{abstract}

\footnotetext{
M. E. L. Arbouw • T. C. G. Egberts $(\bowtie)$

Department of Clinical Pharmacy,

Division Laboratory and Pharmacy,

University Medical Center Utrecht,

PO Box 85500, 3508 GA Utrecht, The Netherlands

e-mail: a.c.g.egberts@umcutrecht.nl
}

M. E. L. Arbouw • T. C. G. Egberts

Division of Pharmacoepidemiology and Pharmacotherapy,

Utrecht Institute for Pharmaceutical Sciences, Faculty of Science,

Utrecht University,

Utrecht, The Netherlands

M. E. L. Arbouw $\cdot$ K. L. L. Movig

Department of Clinical Pharmacy, Medisch Spectrum Twente,

Enschede, The Netherlands

H.-J. Guchelaar

Department of Clinical Pharmacy and Toxicology,

Leiden University Medical Center,

Leiden, The Netherlands

C. Neef

Department of Clinical Pharmacy and Toxicology,

University Hospital Maastricht,

Maastricht, The Netherlands were initially identified. Cases were patients who were hospitalized for the first time after November 1997 for an ischemic event and were matched to as many as four controls. Exposure to dopamine agonists during the year preceding the index date was identified.

Results The study population consisted of 542 cases and 2,155 controls. The mean effect of dopamine agonist use 1 year prior to the index date on ischemic events requiring hospitalization is shown with $95 \%$ probability in the 0.95-1.49 range. Stratified results according to the type of dopamine agonist showed no risk differences between ergoline and nonergoline agonists.

Conclusions This study does not support an association between dopamine agonist use and an increased risk of ischemic events requiring hospitalization.

Keywords Parkinson's disease - Dopaminergic drugs . Ischemic complications

Abbreviations
$\begin{array}{ll}\text { PD } & \text { Parkinson's disease } \\ \text { ICD-9-CM } & \begin{array}{l}\text { International Classification of Diseases 9th } \\ \text { edition }\end{array} \\ \text { DDD } & \text { Defined daily dose } \\ \text { OR } & \text { Odds ratios } \\ \text { CI } & \text { Confidence intervals }\end{array}$

\section{Introduction}

Dopamine agonists (DAs) are mainly used as (initial) monotherapy and adjunctive pharmacotherapy to levodopa in patients with Parkinson's disease (PD). Ergoline DAs 
(bromocriptine, lisuride, cabergoline, pergolide), derivates from ergot alkaloids, were the first DAs available for treating PD. The nonergoline DAs (ropinirole, pramipexole) have become available during the past 10 years. It has been suggested that DAs, and more specifically, ergoline DAs, can cause ischemic complications. In 1993, there was suspicion that use of bromocriptine to suppress postpartum lactation could cause adverse cardiovascular and cerebrovascular effects, mainly acute myocardial infarction and stroke $[1,2]$, but this was not confirmed in a retrospective cohort study [3]. Furthermore, it is known that intermittent, chronic, and excessive use of ergotamine, an ergot alkaloid used to treat migraine, can lead to serious ischemic adverse events such as peripheral ischemia, arterial stenosis, myocardial infarction, and cerebral ischemia [4-6]. A more recent study also demonstrated that overuse of ergotamine, is associated with increased risk of ischemic complications, especially in those using drugs for cardiovascular disease [7]. Furthermore, it has been suggested that DAs could cause peripheral edema [8,9] and orthostatic hypotension [10]. Orthostatic hypotension is a risk factor for coronary heart disease events [11] and ischemic stroke [12]. However, the effect of DAs in general and ergoline DAs specifically on the prevalence of ischemic events in patients with PD has not been studied.

The objective of our study was to evaluate in PD patients the association between the use of DAs and the occurrence of ischemic complications requiring hospitalization, including coronary, peripheral, and cerebral vascular ischemic events.

\section{Methods}

Setting and study design

We performed a nested case-control study using the PHARMO Institute for Drug Outcome Research record linkage system. This includes pharmacy dispensing records from community pharmacies linked to hospital discharge records of all 950,000 community-dwelling residents of 25 population-defined areas in The Netherlands from 1985 onward [13]. Because virtually all patients in The Netherlands are registered with a single community pharmacy, independent of prescriber, pharmacy records are virtually complete with regard to prescription drugs. Participants of the PHARMO population enter the database with the first prescription filled in a PHARMO community pharmacy and are followed till the last prescription. The computerized drug-dispensing histories contain information concerning dispensed drug, dispensing date, prescriber, amount dispensed, prescribed dose regimen, and estimated duration of use. The duration of use of each dispensed drug is estimated by dividing the number of dispensed units by the prescribed number of units to be used per day. Patient information per prescribed drug includes gender and date of birth. The database does not provide information concerning the indications for use of the drugs - in this case the diagnosis of PD.

Hospital discharge records are obtained from the Dutch Medical Register (LMR) from PRISMANT, an institute that since the 1960s collects all hospital discharge records in The Netherlands in a standardized format. These records include detailed information concerning discharge diagnoses, diagnostic, surgical and treatment procedures, type and frequency of consultations with medical specialists, and dates of hospital admission and discharge. All diagnoses are coded according to the International Classification of Diseases, 9th edition (ICD-9-CM).

\section{Study base}

All patients with at least one prescription for a levodopacontaining drug after the age of 55 between 1 January 1994 and 31 December 2006 were initially identified. Van de Vijver and colleagues have shown that $94 \%$ of patients $>55$ years who are using levodopa in The Netherlands were diagnosed with PD [14]. In addition, to be included in the study base, all patients were required to be registered as active in the PHARMO database after 1 November 1997.

\section{Case and control definition}

Cases were defined as all patients from the study base who were hospitalized for the first time after 1 November 1997 for a coronary, peripheral, or cerebral vascular event. This date was chosen to show a contrast between ergoline and nonergoline DAs, because the nonergoline agonists were introduced in The Netherlands shortly after that date. These diagnoses are: ischemic heart disease (ICD-9-CM codes 410, 411, and 413), cerebral ischemia (ICD-9-CM codes 433-436, 437.0, 437.1, and 437.6), and peripheral ischemia [Raynaud's syndrome (ICD-9-CM code 443.0), unspecified peripheral vascular disease (ICD-9-CM code 443.9), vascular insufficiency of intestine (ICD-9-CM code 557.0 and 557.9), and gangrene (ICD-9-CM code 785.4)]. The index date was the date of hospital admission. Further criteria for both cases and controls were at least 12 months of observation in PHARMO before the index date, and the theoretical end date of the last dispensed drug in the PHARMO database had to be no more than 180 days before the index date. For each case patient, up to four control patients who were at risk for an ischemic event on the corresponding index date were randomly sampled. Controls were matched to case patients according to gender, duration of prescription history available (within 365 days), and age (within 5 years). Each control was included only once. 


\section{Exposure definition}

For all cases and controls, we identified exposure to all DAs during the 1 year preceding the index date. DAs included the ergoline agonists bromocriptine, cabergoline, pergolide, lisuride, quinagolide; and the nonergoline agonists ropinirole and pramipexole. Patients were classified as a DA user when they had at least one prescription within 1 year before the index date and as no user if they had no prescription for any DA within 1 year before the index date. Subsequently, according to the type of DA used, users were stratified as using an ergoline or a nonergoline DA. Those who received more than one type of DA in the year before their index date were grouped according to the agonist group prescribed for the longest period during 12 months. If two or more agonists were taken for the same number of months, patients were classified according to the most recent use. Current use was defined as use that was still in effect at the index date, recent use as use within 6 months before the index date, and past use as use within 12 months before the index date. Total DA consumption per patient was estimated by the sum of defined daily doses (DDDs) dispensed 1 year before the index date. One DDD was defined as $40 \mathrm{mg}$ bromocriptine, $3 \mathrm{mg}$ cabergoline, $3 \mathrm{mg}$ pergolide, $3.6 \mathrm{mg}$ lisuride (based on $0.6 \mathrm{mg}$ for indication lactation inhibition), $0.075 \mathrm{mg}$ quinagolide, $6 \mathrm{mg}$ ropinirole, or $2.5 \mathrm{mg}$ pramipexole (http://www.whocc.no/atc_ddd_index).

\section{Potential confounding factors}

To adjust for factors that may confound the association between ergoline DA use and the occurrence of ischemic complications, the following covariates were studied as potential confounders: prior hospitalization before November 1997 due to ischemic event, other prior hospitalization 1 year prior to the index date, comedication use prior to the index date (fenfluramine, dexfluramine, ergotamine, dihydroergotamine or methysergide), other comedication use 1 year prior to the index date [levodopa, antidepressants, antidiabetics, gastrointestinal drugs (proton pump inhibitors, H2-antagonists), nonsteroidal anti-inflammatory drugs (NSAIDs), hormones (orally administered anticonceptives and hormonal replacement therapy), and drugs to treat cardiovascular disease (angiotensin-converting enzyme inhibitors, beta-blockers, calcium antagonists, diuretics, nitrates, digoxin, vitamin-K antagonists, antiplatelet therapy, lipid-lowering therapy)].

\section{Data analysis}

For cases and controls, the prevalence of each characteristic at or during the period 1 year prior to the index date was determined. Differences between cases and controls were examined using Fisher's exact test for categorical variables and independent samples Student's $t$ test for continuous variables. Conditional logistic regression was used to estimate the strength of the association between the use of DAs and ischemic complications requiring hospitalization, expressed as crude and adjusted odds ratios (OR) with $95 \%$ confidence intervals (CI). The overall logistic regression model included all potentially confounding factors that changed the natural logarithm of the risk estimate between DA use and the occurrence of ischemic complications by $>10 \%$. In a subanalysis, patients were stratified to current use, recent use, and past use. Furthermore, patients were categorized to the intensity of DA use: $0,>0$ to $<150$, 150 to $<300,300$ to $<450$, and $\geq 450$ DDD. Microsoft Access was used for database management and internal quality procedures. All statistical analyses were performed with SPSS (version 16.0.2).

\section{Results}

A flow chart of inclusion is presented in Fig. 1. The study base consisted of 8,094 patients. We identified 542 case patients who were hospitalized due to ischemic events and 2,155 matched control patients.

Characteristics of the study population at the index date are described in Table 1. Cases were hospitalized more frequently than controls and more frequently used drugs used in cardiovascular, gastrointestinal, and diabetic treatment. There was no difference in amount of levodopa users between cases and controls. Most ischemic events were of a cardiovascular nature (47.4\%). Cerebrovascular events occurred in $45.0 \%$ of cases and peripheral ischemic events in $7.6 \%$. Four of the 542 case patients $(0.7 \%)$ were hospitalized for the diagnosis of valvular heart disease ever before the index date.

The final regression model included drugs to treat cardiovascular disease, prior hospitalization 1 year before the index date, and prior hospitalization due to ischemic event before November 1997. Table 2 shows that the mean effect of DA use 1 year prior to the index date on ischemic events requiring hospitalization was with $95 \%$ probability in the $0.95-1.49$ range. Stratified results according to DA type used show that there were no risk differences between ergoline and nonergoline DA users. Risk estimates for ischemic events after stratification to current, recent, or past use remained in the same order (Table 3). There was no relationship between the intensity of DA use expressed as number of DDD and the risk of ischemic events requiring hospitalization.

We performed an exploratory analysis in which we stratified users of an ergoline DA (1 year before the index date) to type of DA used $>1$ year before the index date. 


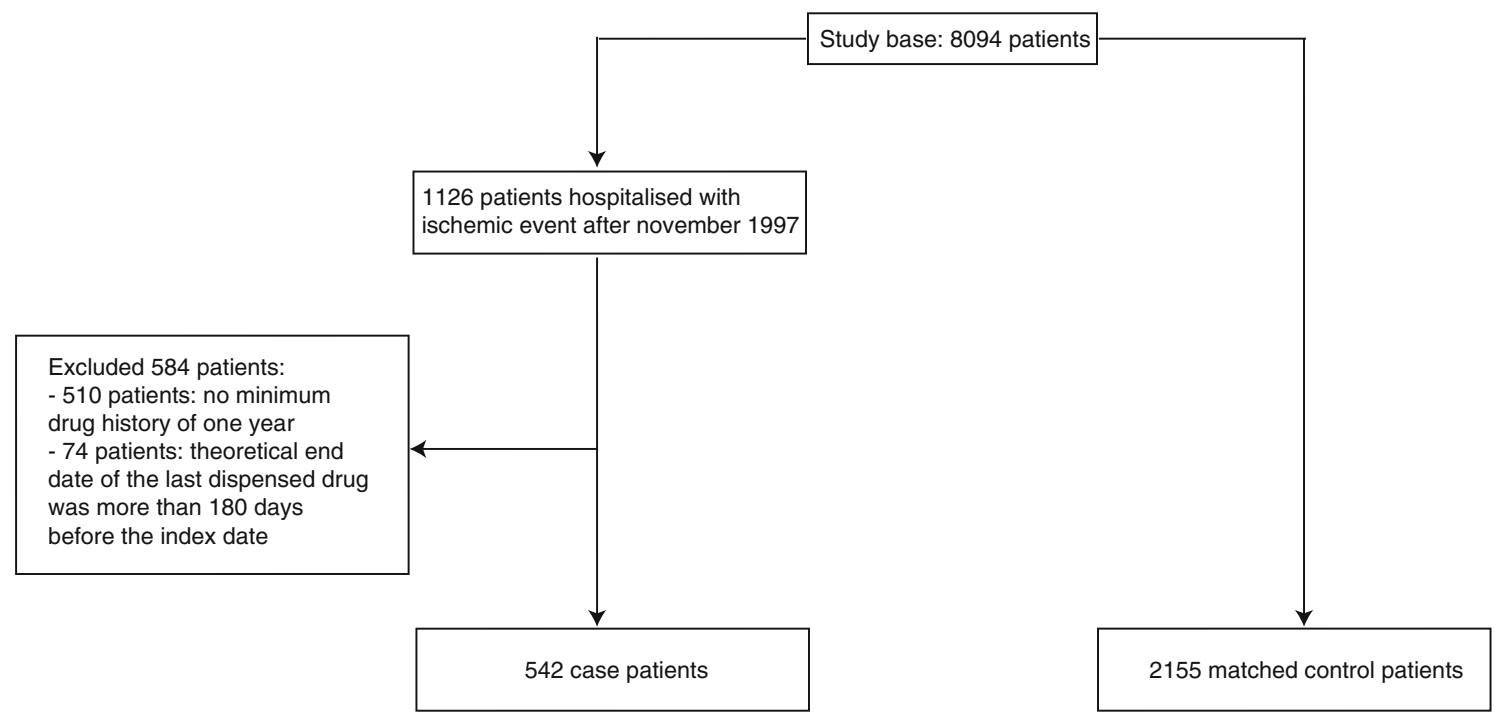

Fig. 1 Case and control patient inclusion

Table 1 Baseline characteristics of cases (ischemic event) and controls (no ischemic event)

\begin{tabular}{|c|c|c|c|}
\hline Characteristics & $\begin{array}{l}\text { Cases } \\
(n=542), \\
\text { no. }(\%)\end{array}$ & $\begin{array}{l}\text { Controls } \\
(n=2,155), \\
\text { no. }(\%)\end{array}$ & $P$ value* \\
\hline \multicolumn{3}{|l|}{ Gender } & \multirow[t]{3}{*}{ NS } \\
\hline Female & $227(41.9)$ & $907(42.1)$ & \\
\hline Male & $315(58.1)$ & $1,248(57.9)$ & \\
\hline Age, years, mean (SD) & $75.4(8.0)$ & $75.2(7.9)$ & NS \\
\hline $\begin{array}{l}\text { Prior hospitalization due to } \\
\text { ischemic event before } \\
\text { November } 1997\end{array}$ & $44(8.1)$ & $0(0)$ & $<0.001$ \\
\hline $\begin{array}{l}\text { Other prior hospitalization } \\
\text { (1 year prior to index date) }\end{array}$ & $206(38.0)$ & $555(25.8)$ & $<0.001$ \\
\hline \multicolumn{4}{|l|}{ Comedication } \\
\hline Fenfluramine & $1(0.2)$ & $3(0.1)$ & NS \\
\hline Dexfluramine & $2(0.4)$ & $4(0.2)$ & NS \\
\hline Ergotamine & $4(0.7)$ & $11(0.5)$ & NS \\
\hline Methysergide & $0(0)$ & $0(0)$ & NS \\
\hline \multicolumn{4}{|c|}{ Comedication ( 1 year prior to index date) } \\
\hline Antidepressants & $50(9.2)$ & $208(9.7)$ & NS \\
\hline Benzodiazepines & $135(24.9)$ & $480(22.3)$ & NS \\
\hline Antidiabetics & $55(10.1)$ & $134(6.2)$ & 0.001 \\
\hline $\begin{array}{l}\text { Orally administered } \\
\text { contraceptives }\end{array}$ & $0(0)$ & $5(0.2)$ & NS \\
\hline HRT & $7(1.3)$ & $43(2.0)$ & NS \\
\hline Gastrointestinal & $103(19.0)$ & $264(12.3)$ & $<0.001$ \\
\hline NSAIDs & $119(22.0)$ & $400(18.6)$ & NS \\
\hline Cardiovascular & $269(49.6)$ & $767(35.6)$ & $<0.001$ \\
\hline Levodopa & $391(72.1)$ & $1,563(72.5)$ & NS \\
\hline
\end{tabular}

$N S$ not significant, $S D$ standard deviation, $H R T$ hormone replacement therapy, NSAIDs nonsteroidal anti-inflammatory drugs

*Fisher's exact test for comparison of proportions and independent $t$ samples for comparisons of means between cases and controls
Accordingly, we stratified users of a nonergoline DA (1 year before the index date) to type of DA used $>1$ year before the index date. A main finding was that compared to never use, nonergoline DA use with ergoline use $>1$ year before the index date was associated with a higher risk of ischemic events (adjusted OR 1.72; 95\% CI 1.33-2.07).

\section{Discussion}

This study does not support an association between DA use and an increased risk of ischemic events requiring hospitalization. Type of DA used (ergoline or nonergoline) and intensity of use does not influence the risk estimate. Pharmacologically, we expected an increased risk of

Table 2 Association between use of a dopamine agonist (DA) in general and stratified by type 1 year prior to the index date and hospitalization due to ischemic event

\begin{tabular}{|c|c|c|c|c|}
\hline & $\begin{array}{l}\text { Cases } \\
(n=542), \\
\text { no. }(\%)\end{array}$ & $\begin{array}{l}\text { Controls } \\
(n=2,155), \\
\text { no. }(\%)\end{array}$ & $\begin{array}{l}\text { Crude OR } \\
(95 \% \mathrm{CI})\end{array}$ & $\begin{array}{l}\text { Adjusted OR } \\
(95 \% \mathrm{CI})\end{array}$ \\
\hline $\begin{array}{l}\text { No dopamine } \\
\text { agonist use }\end{array}$ & $\begin{array}{l}366 \\
(67.5)\end{array}$ & $\begin{array}{l}1,516 \\
(70.3)\end{array}$ & 1.0 (Ref) & 1.0 (Ref) \\
\hline $\begin{array}{l}\text { Dopamine } \\
\text { agonist use }\end{array}$ & $\begin{array}{l}176 \\
(32.5)\end{array}$ & $\begin{array}{l}639 \\
(29.7)\end{array}$ & $\begin{array}{l}1.16 \\
(0.94-1.43)\end{array}$ & $\begin{array}{l}1.19 \\
\quad(0.95-1.49)\end{array}$ \\
\hline Ergot use & $\begin{array}{l}103 \\
(19.0)\end{array}$ & $\begin{array}{l}381 \\
(17.7)\end{array}$ & $\begin{array}{l}1.13 \\
(0.88-1.46)\end{array}$ & $\begin{array}{l}1.22 \\
(0.93-1.60)\end{array}$ \\
\hline Nonergot use & $\begin{array}{l}73 \\
(13.5)\end{array}$ & $\begin{array}{l}258 \\
(12.0)\end{array}$ & $\begin{array}{l}1.20 \\
(0.89-1.62)\end{array}$ & $\begin{array}{l}1.15 \\
(0.83-1.57)\end{array}$ \\
\hline
\end{tabular}

Adjusted for use of drugs to treat cardiovascular disease and prior hospitalization 1 year before the index date and for prior hospitalization due to ischemic event before November 1997

OR odds ratio, $C I$ confidence interval, Ref reference 
Table 3 Association between use of all dopamine agonists (DAs), ergoline DAs, and nonergoline DAs 1 year prior to the index date and hospitalization due to ischemic event stratified to current, recent, and past use

\begin{tabular}{|c|c|c|c|c|}
\hline & $\begin{array}{l}\text { Cases } \\
(n=542), \\
\text { no. }(\%)\end{array}$ & $\begin{array}{l}\text { Controls } \\
(n=2,155), \\
\text { no. }(\%)\end{array}$ & $\begin{array}{l}\text { Crude OR } \\
(95 \% \mathrm{CI})\end{array}$ & $\begin{array}{l}\text { Adjusted OR } \\
(95 \% \mathrm{CI})\end{array}$ \\
\hline $\begin{array}{l}\text { No dopamine } \\
\text { agonist use }\end{array}$ & $366(67.5)$ & $1,516(70.3)$ & 1.0 (Ref) & 1.0 (Ref) \\
\hline \multicolumn{5}{|c|}{ All dopamine agonists } \\
\hline Current use & $60(11.1)$ & $218(10.1)$ & $\begin{array}{l}1.16 \\
(0.84-1.60)\end{array}$ & $\begin{array}{l}1.11 \\
\quad(0.79-1.56)\end{array}$ \\
\hline Recent use & $103(19.0)$ & $381(17.7)$ & $\begin{array}{l}1.13 \\
(0.88-1.46)\end{array}$ & $\begin{array}{l}1.21 \\
(0.93-1.59)\end{array}$ \\
\hline Past use & $13(2.4)$ & $40(1.9)$ & $\begin{array}{l}1.36 \\
(0.72-2.58)\end{array}$ & $\begin{array}{l}1.40 \\
(0.73-2.69)\end{array}$ \\
\hline \multicolumn{5}{|l|}{ Ergot use } \\
\hline Current use & $5(0.9)$ & $23(1.1)$ & $\begin{array}{l}0.91 \\
\quad(0.34-2.42)\end{array}$ & $\begin{array}{l}0.79 \\
\quad(0.26-2.34)\end{array}$ \\
\hline Recent use & $90(16.6)$ & $342(15.9)$ & $\begin{array}{l}1.10 \\
(0.84-1.43)\end{array}$ & $\begin{array}{l}1.20 \\
(0.91-1.60)\end{array}$ \\
\hline Past use & $8(1.5)$ & $16(0.7)$ & $\begin{array}{l}2.12 \\
\quad(0.89-5.04)\end{array}$ & $\begin{array}{l}2.15 \\
(0.87-5.33)\end{array}$ \\
\hline \multicolumn{5}{|l|}{ Nonergot use } \\
\hline Current use & $55(10.1)$ & $195(9.0)$ & $\begin{array}{l}1.20 \\
(0.86-1.68)\end{array}$ & $\begin{array}{l}1.15 \\
\quad(0.81-1.63)\end{array}$ \\
\hline Recent use & $13(2.4)$ & $39(1.8)$ & $\begin{array}{l}1.41 \\
(0.73-2.69)\end{array}$ & $\begin{array}{l}1.27 \\
(0.64-2.52)\end{array}$ \\
\hline Past use & $5(0.9)$ & $24(1.1)$ & $\begin{array}{l}0.88 \\
\quad(0.33-2.33)\end{array}$ & $\begin{array}{l}0.92 \\
\quad(0.34-2.47)\end{array}$ \\
\hline
\end{tabular}

Adjusted for use of drugs to treat cardiovascular disease and prior hospitalization 1 year before the index date and for prior hospitalization due to ischemic event before November 1997

$O R$ odds ratio, $C I$ confidence interval, recent use $>0-180$ days before index date, past use $>180-360$ days before index date

ischemic events with DA use in general, and probably an even higher risk with ergoline DA use specifically. First, it is known that all DAs may cause orthostatic hypotension as a direct effect and from interactions with baroreflex and sympathoneural pathophysiological mechanisms that are part of the disease process [10]. Orthostatic hypotension is a risk factor, but probably not a major risk factor, for coronary heart disease events [11] and ischemic stroke [12]. Coronary heart disease events are explained by rapid displacement of blood volume to the lower body - up to $30 \%$ of thoracic blood volumethat causes postural blood pressure change [11]. Ischemic stroke is explained by decreased cerebral perfusion due to the drop in pressure, and indirectly by the contribution of postural hypotension to cerebral hypoperfusion through myocardial ischemia and concomitant hemodynamic instability [12]. Second, peripheral edema has been reported as a rare complication of ergoline DAs [15]. Recent studies demonstrate that peripheral edema occurs in up to $16 \%$ of users of the nonergoline DA pramipexole [8,9], with most cases occurring after 2 years of treatment [8] and with a higher risk in patients with coronary artery disease [9]. Thus, peripheral edema is now suggested as a more general effect of DA therapy, which might increase the risk of adverse cardiovascular events. Finally, it is suggested that short-term use of the ergoline DA bromocriptine to suppress postpartum lactation could cause adverse cardiovascular and cerebrovascular effects, mainly acute myocardial infarction and stroke, due to vasospastic events $[1,2]$. A possible mechanism would be coronary artery spasm with possible thrombus formation at the spasm site [1]. However, in a retrospective cohort study, this suspicion could not be confirmed [3]. Overuse of ergotamine, another ergot alkaloid used to treat migraine, has been associated with an increased risk of ischemic events requiring hospitalization [7]. In PD treatment, DAs are used long term. This could implicate a higher risk of adverse cardiovascular and cerebrovascular effects by ergoline DAs. Apparently, however, DAs do not exert these effects in a manner that leads to an increased risk of ischemic events. Also, there was no association between cumulative dose used in the year before the index date and ischemic events.

Some patients in this study may have discontinued therapy $>1$ year before the index date; however, we investigated exposure to DAs for only 1 year preceding the index date. A history in the PHARMO database of $>1$ year prior to the index date was not an inclusion criterion. In a exploratory analysis, we demonstrated that users of a nonergoline DA 1 year before the index date with ergoline use $>1$ year before the index date had a higher risk of ischemic events compared to never users (adjusted OR $1.72 ; 95 \%$ CI 1.33-2.07). Thus, it seems that past use of ergoline DAs increases the risk of ischemic events. However, we have no clear explanation for this exploratory result. Recently, several studies have been published supporting a causal relationship between the occurrence of irreversible valvular heart disease and treatment with the ergoline DAs pergolide and cabergoline [16, 17]. It is suggested that this valvulopathy is mediated by stimulation of $5-\mathrm{HT}_{2 \mathrm{~B}}$ receptors, causing inappropriate mitogenic stimulation of normally quiescent valve cells [18]. However, hospitalization for the indication valvular heart disease is coded by ICD-9-CM codes (i.e., 424 and 425) other than those used in our study. In addition, only $0.7 \%$ of our case patients were hospitalized for the diagnosis of valvular heart disease before the index date. Thus, we do not believe that the increased risk of ischemic events by past ergoline DA use could be explained by a higher risk of valvular heart disease.

Several limitations of this study should be mentioned. First, hospital ICD-9 codes may not always be accurate. 
Dutch validity studies for the ICD-9 codes that we used have not been published. False negatives, meaning that among the controls one could find some cases, would have weakened our results. False positives, i.e., not all cases were truly cases, would also lead to weaker results. Second, the intensity of DA use may be a marker of PD severity. PD seems to be not only a movement disorder due to dopamine loss in the nigrostriatal system of the brain, but it also involves postganglionic sympathetic noradrenergic lesions. Orthostatic hypotension frequently occurs in patients with $\mathrm{PD}$, irrespective of dopaminergic medication [10]. However, excess risk of adverse coronary artery events or ischemic stroke has not been reported among patients with PD $[19,20]$. Thus, disease severity itself seems not to be a confounding factor. Furthermore, although adjusted for potential confounders, residual confounding may exist because a few factors known to be associated with increased risk of coronary and cerebrovascular complications-such as smoking, family history, obesity, and lack of fitness - were unknown. Last, there is small chance that PD patients treated with DAs may not have been identified. Patients with at least one prescription for a levodopa-containing drug after the age of 55 were included in the study base. Although all PD patients will eventually start levodopa, some patients may have begun treatment outside the inclusion period. Strengths of this study are that our sample size was substantial, and we routinely collected longitudinal data on drug exposure and hospitalizations. Patients were included irrespective of socioeconomic status: the study was population-based and provided real-life data on DA intake. Overall, contrary to case reports, this populationbased study does not provide evidence to support an association between ischemic events and DA use-or more specifically_ergoline DA use.

Conflicts of interest The division of Pharmacoepidemiology \& Pharmacotherapy employing authors Arbouw and Egberts has received unrestricted funding for pharmacoepidemiological research from GlaxoSmithKline, Novo Nordisk, the privately/publicly funded Top Institute Pharma (www.tipharma.nl, as well as cofunding from universities, government, and industry), the Dutch Medicines Evaluation Board, and the Dutch Ministry of Health.

Open Access This article is distributed under the terms of the Creative Commons Attribution Noncommercial License which permits any noncommercial use, distribution, and reproduction in any medium, provided the original author(s) and source are credited.

\section{References}

1. Larrazet F, Spaulding C, Lobreau HJ, Weber S, Guerin F (1993) Possible bromocriptine-induced myocardial infarction. Ann Intern Med 118:199-200

2. Iffy L, TenHove W, Frisoli G (1986) Acute myocardial infarction in the puerperium in patients receiving bromocriptine. Am J Obstet Gynecol 155:371-372

3. Herings RM, Stricker BH (1995) Bromocriptine and suppression of postpartum lactation. The incidence of adverse cardiovascular effects in women of child-bearing age. Pharm World Sci 17:133-137

4. Meyler WJ (1996) Side effects of ergotamine. Cephalalgia 16:5-10

5. Senter HJ, Lieverman AN, Pinto R (1976) Cerebral manifestations of ergotism. Report of a case and review of the literature. Stroke 7:88-92

6. Tfelt-Hansen P, Saxena PR, Dahlof C, Pascual J, Lainez M, Henry P, Diener H, Schoenen J, Ferrari MD, Goadsby PJ (2000) Ergotamine in the acute treatment of migraine: a review and European consensus. Brain 123(Pt 1):9-18

7. Wammes-van der Heijden EA, Rahimtoola H, Leufkens HG, Tijssen CC, Egberts AC (2006) Risk of ischemic complications related to the intensity of triptan and ergotamine use. Neurology 67:1128-1134

8. Biglan KM, Holloway RG Jr, McDermott MP, Richard IH (2007) Risk factors for somnolence, edema, and hallucinations in early Parkinson disease. Neurology 69:187-195

9. Kleiner-Fisman G, Fisman DN (2007) Risk factors for the development of pedal edema in patients using pramipexole. Arch Neurol 64:820-824

10. Goldstein DS (2003) Dysautonomia in Parkinson's disease: neurocardiological abnormalities. Lancet Neurol 2:669-676

11. Rose KM, Tyroler HA, Nardo CJ, Arnett DK, Light KC, Rosamond W, Sharrett AR, Szklo M (2000) Orthostatic hypotension and the incidence of coronary heart disease: the Atherosclerosis Risk in Communities study. Am J Hypertens 13:571-578

12. Eigenbrodt ML, Rose KM, Couper DJ, Arnett DK, Smith R, Jones D (2000) Orthostatic hypotension as a risk factor for stroke: the atherosclerosis risk in communities (ARIC) study, 1987-1996. Stroke 31:2307-2313

13. Herings RM, Bakker A, Stricker BH, Nap G (1992) Pharmacomorbidity linkage: a feasibility study comparing morbidity in two pharmacy based exposure cohorts. J Epidemiol Community Health 46:136-140

14. Van de Vijver DA, Stricker BH, Breteler MM, Roos RA, Porsius AJ, de Boer A (2001) Evaluation of antiparkinsonian drugs in pharmacy records as a marker for Parkinson's disease. Pharm World Sci 23:148-152

15. Blackard WG (1993) Edema-an infrequently recognized complication of bromocriptine and other ergot dopaminergic drugs. Am J Med 94:445

16. Schade R, Andersohn F, Suissa S, Haverkamp W, Garbe E (2007) Dopamine agonists and the risk of cardiac-valve regurgitation. N Engl J Med 356:29-38

17. Zanettini R, Antonini A, Gatto G, Gentile R, Tesei S, Pezzoli G (2007) Valvular heart disease and the use of dopamine agonists for Parkinson's disease. N Engl J Med 356:39-46

18. Roth BL (2007) Drugs and valvular heart disease. N Engl J Med 356:6-9

19. Mastaglia FL, Johnsen RD, Kakulas BA (2002) Prevalence of stroke in Parkinson's disease: a postmortem study. Mov Disord 17:772-774

20. Jellinger KA (2003) Prevalence of stroke in Parkinson's disease. Mov Disord 18:723-724 